\title{
Service life assessment of different types of plasters applied for the renovation of architectural heritage
}

\author{
V. Kočí, J. Maděra, \& R. Černý \\ Department of Materials Engineering and Chemistry, \\ Faculty of Civil Engineering, Czech Technical University in Prague, \\ Czech Republic
}

\begin{abstract}
The service life of several renovation plasters applied on historical masonry is assessed. Beside traditional plasters, which are usually preferred by the preservation authorities, newly developed plasters on the scientific field are also investigated. The historical masonry is represented by solid bricks and selected type of sandstone. All the simulations with experimentally measured material parameters are performed for the dynamic climatic conditions of Prague. The results indicate that traditional plasters with very good mechanical properties do not always ensure the best solution from the point of view of the service life of building envelopes. The newly developed plasters evince much better hygrothermal performance, so that the presence of freeze/thaw cycles can be essentially neglected. Furthermore, the applied experimental-computational approach appears as an effective tool for the identification of tailored solutions for the particular types of historical building envelopes.
\end{abstract}

Keywords: solid brick, sandstone, plasters, renovation, computations, freeze/thaw resistance, service life.

\section{Introduction}

Renovation of historical buildings' surface layers is usually a very complicated issue because of the strict supervision of preservation authorities which often do not allow application of newly developed materials with much better properties and performance. Application of traditional materials and methods compatible with original treatments remain always as the main standard. Their choice is 
determined by previous experience and the fact, whether they were found suitable at an application on some other buildings before.

The service life of new surface layers is estimated on the basis of experience as well because too few parameters are known for a reliable durability estimate. The choice of a material for reconstruction is then often less suitable regarding the moisture content in the masonry which leads to shorter service life of surface layers than it is expected.

The solution of the problem of damage of surface layers of historical buildings can be brought by the method presented in this paper which was not used frequently so far. It consists in a combination of computational and experimental approaches. In the experimental part, durability of several traditional and renovation plasters is determined in terms of their frost resistance. In the subsequent step, the number of frost cycles in a real structure is identified using a computational analysis. Because this method brings results without influencing the real structure, it has all the predispositions to be accepted by preservation authorities.

In this paper, several different types of historical materials of load-bearing structure and several different plasters are under consideration. Conclusions on the most advantageous material composition with respect to the service life of exterior renders are drawn.

\section{Computational analysis}

The computational analysis was performed using the computer code HEMOT [1], which was developed at the Department of Materials Engineering and Chemistry, Faculty of Civil Engineering, Czech Technical University in Prague. It works on the basis of the general finite element package SIFEL [2]. The analysis can be done only if several input parameters are gathered. It is necessary to select proper mathematical model, draw analyzed construction detail including its mesh, assign boundary conditions and material parameters and choose time interval and specify time step of simulation. All these input parameters are described in the following subsections.

\subsection{Scheme of construction detail}

As representative historical building materials, solid ceramic brick and sandstone were selected. These materials were commonly used not only on the Czech territory but also in other European countries. The sandstone comes from quarry Záměl which is located in the Czech Republic. The load bearing wall in thickness $500 \mathrm{~mm}$ was provided with external $(20 \mathrm{~mm})$ and internal $(10 \mathrm{~mm})$ plasters. In this paper, three different plasters were analyzed: common limecement plaster (LCP) representing the traditional material, lime plaster with metakaolin addition (LPMA) and lime plaster with addition of ceramic powder (LPC). The last two plasters represent new way of plasters development on the scientific field. The scheme of building envelope is shown in Figure 1. 


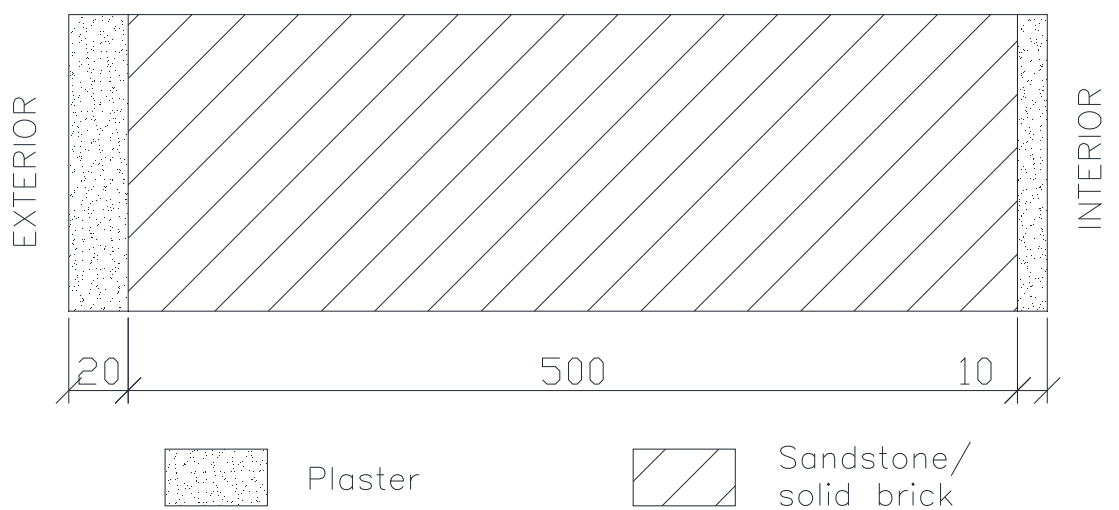

Figure 1: Scheme of analyzed construction detail.

\subsection{Material parameters}

The sandstone from Záměl quarry can be characterized as medium-grained glauconitic sandstone with schistose texture. It is mostly formed by quartz (79\%), glauconit (9\%), feldspar (4\%) and muscovite (1\%).

All the basic physical, heat and moisture transport and storage parameters used as input data in presented calculations were measured in the laboratories of the Department of Materials Engineering and Chemistry, Faculty of Civil Engineering, Czech Technical University in Prague [3-7] according to the methodology presented in [8]. The gathered laboratory data are summarized in Tables $1-3$, where the following symbols are used: : $\rho$ - bulk density $\left[\mathrm{kg} / \mathrm{m}^{3}\right], \psi$ - porosity [\%], $c$ - specific heat capacity $[\mathrm{J} / \mathrm{kgK}], \mu$ - water vapor diffusion resistance factor [-], $\lambda$ - thermal conductivity $[\mathrm{W} / \mathrm{mK}], \kappa_{a p p}-$ apparent moisture diffusivity $\left[\mathrm{m}^{2} / \mathrm{s}\right]$.

Table 1: $\quad$ Material characteristics - part I.

\begin{tabular}{|l|c|c|}
\hline Parameter & Sandstone & Solid brick \\
\hline$\rho\left[\mathrm{kg} \mathrm{m}^{-3}\right]$ & 2076 & 1831 \\
\hline$\psi[\%]$ & 22.8 & 27.9 \\
\hline$c\left[\mathrm{~J} \mathrm{~kg}^{-1} \mathrm{~K}^{-1}\right]$ & $694-1098$ & $825-1254$ \\
\hline$\mu[-]$ & $6.9-11.8$ & $6.3-22.1$ \\
\hline$\lambda_{\text {dry }}\left[\mathrm{W} \mathrm{m}^{-1} \mathrm{~K}^{-1}\right]$ & 2.10 & 0.590 \\
\hline$\lambda_{\text {sat }}\left[\mathrm{W} \mathrm{m}^{-1} \mathrm{~K}^{-1}\right]$ & 3.88 & 1.735 \\
\hline$\kappa_{\text {app }}\left[\mathrm{m}^{2} \mathrm{~s}^{-1}\right]$ & $7.76 \mathrm{e}-7$ & $3.16 \mathrm{e}-7$ \\
\hline
\end{tabular}


Table 2: $\quad$ Material characteristics - part II.

\begin{tabular}{|l|c|c|c|}
\hline Parameter & LCP & LPC & LPMA \\
\hline$\rho\left[\mathrm{kg} \mathrm{m}^{-3}\right]$ & 1550 & 1713 & 1745 \\
\hline$\psi[\%]$ & 40.0 & 35.6 & 33.0 \\
\hline$c\left[\mathrm{~J} \mathrm{~kg}^{-1} \mathrm{~K}^{-1}\right]$ & 1200 & 831 & 610 \\
\hline$\mu[-]$ & 7.00 & $9.23-27.26$ & 10 \\
\hline$\lambda_{\text {dry }}\left[\mathrm{W} \mathrm{m}^{-1} \mathrm{~K}^{-1}\right]$ & 0.700 & 0.669 & 0.845 \\
\hline$\lambda_{\text {sat }}\left[\mathrm{W} \mathrm{m}^{-1} \mathrm{~K}^{-1}\right]$ & 2.400 & 2.415 & 2.400 \\
\hline$\kappa_{\text {app }}\left[\mathrm{m}^{2} \mathrm{~s}^{-1}\right]$ & $7.30 \mathrm{e}-7$ & $6.60 \mathrm{e}-7$ & $3.90 \mathrm{e}-8$ \\
\hline
\end{tabular}

Table 3: Number of freeze/thaw cycles causing apparent damage.

\begin{tabular}{|l|c|c|c|}
\hline Material & LCP & LPC & LPMA \\
\hline Freeze/thaw cycles & 103 & 5 & 40 \\
\hline
\end{tabular}

\subsection{Mathematical model}

The transport of heat and moisture was described by balance equations of moisture formulated in Künzel's mathematical model [9]. It belongs to the most frequently used mathematical models because of its several advantages such as utilization of relative humidity $\varphi$ for description of coupled water and water vapor transport, which allows moisture content to be expressed by continuous quantity on material interface. It also contains several simplifications while the main phenomena are kept. Therefore, it requires only tight set of input parameters which makes it predestined for wide application in the field of building physics. This model was verified and successfully applied in numerous hygrothermal simulations before (e.g. [10]).

\subsection{Boundary conditions and time interval of simulation}

Dynamic climatic conditions in the form of Prague's test reference year (TRY) were applied on exterior side of analyzed building envelopes in order to obtain as realistic results as possible. TRY contains long term average hourly values of several weather parameters such as temperature, relative humidity, wind velocity, wind direction, rainfalls or sun radiation. These data were obtained using Meteonorm software [11]. The boundary conditions on interior side of building envelopes were assumed as constant and were set according to the relevant thermal standard [12] to $21^{\circ} \mathrm{C}$ and $55 \%$ of relative humidity.

The results of hygrothermal simulations have to be evaluated after a certain period of time which is necessary for the properties to achieve a kind of dynamic equilibrium, as the hygric and thermal properties of building materials used as input parameters depend on the state variables such as temperature or moisture content. Therefore, the results of hygrothermal performance presented in this paper will be related to the fifth year of simulation which is, according to our previous experience, long enough for a development of cyclic hygrothermal behavior. 


\subsection{Service life estimation process}

Service life of external plasters from the point of view of frost resistance is estimated as a share of experimentally determined number of freeze/thaw cycles which the plaster is capable to resist to and number of freeze/thaw cycles identified in reference year in the plaster using computational analysis.

The identification of appearance of freeze/thaw cycles was performed in point located $2 \mathrm{~mm}$ under the external surface. Even the number of freeze/thaw cycles would be higher on the surface, volume increase related to water-ice phase change will not cause such damage as volume increase under the surface. Moreover, effects of changes of weather conditions remain still significant in this point.

One freeze/thaw cycle can be counted only when temperature drops below zero and at the same time moisture content reaches hygroscopic range. That means in other words, that water occurred in liquid phase is exposed to freeze. These conditions have to be met at least for two hours as well as the gap between two cycles in order to full realization of phase change.

\section{Results and discussion}

The computational simulations of hygrothermal performance of envelopes of historical buildings using experimentally measured material parameters pointed out that the results may vary, depending on type of load bearing material as well as on type of external finish. Based on this fact, combined experimentalcomputational approach seems to be a very effective tool for proper choice of optimal material combination.

Even though lime-cement plaster, representing the traditional finishing material, has very good mechanical properties as it is capable to stand up to 103 freeze/thaw cycles (see Table 3), its hygrothermal performance is the worst from all the investigated plasters. Therefore, its mechanical properties can be easily neglected by increased number of freeze/thaw cycles appearing during reference year which limit its service life. In the case of solid brick as the load bearing material, 8 freeze/thaw cycles were counted. This would lead to first sings of damage approximately after 13 years. Slightly better outlook can be expected in the case of sandstone, where only 6 freeze/thaw cycles were counted. Thus, the service life of this plaster will be limited to 17 years. The hygrothermal performance of LCP applied on brick wall is captured in Figure 2. It is obvious, that moisture content reaches hygroscopic range very frequently due to high moisture diffusivity, which is dangerous especially during winter season when freeze/thaw cycles may occur.

The higher service life of external finishes can be achieved by improving their hygrothermal properties at the expense of mechanical in order to reduce or eliminate one of the essential conditions for creation of freeze/thaw cycle overhygroscopic moisture content. Practically it leads to partial or full replacement of cement, which is the main bearer of strength, by other admixtures 

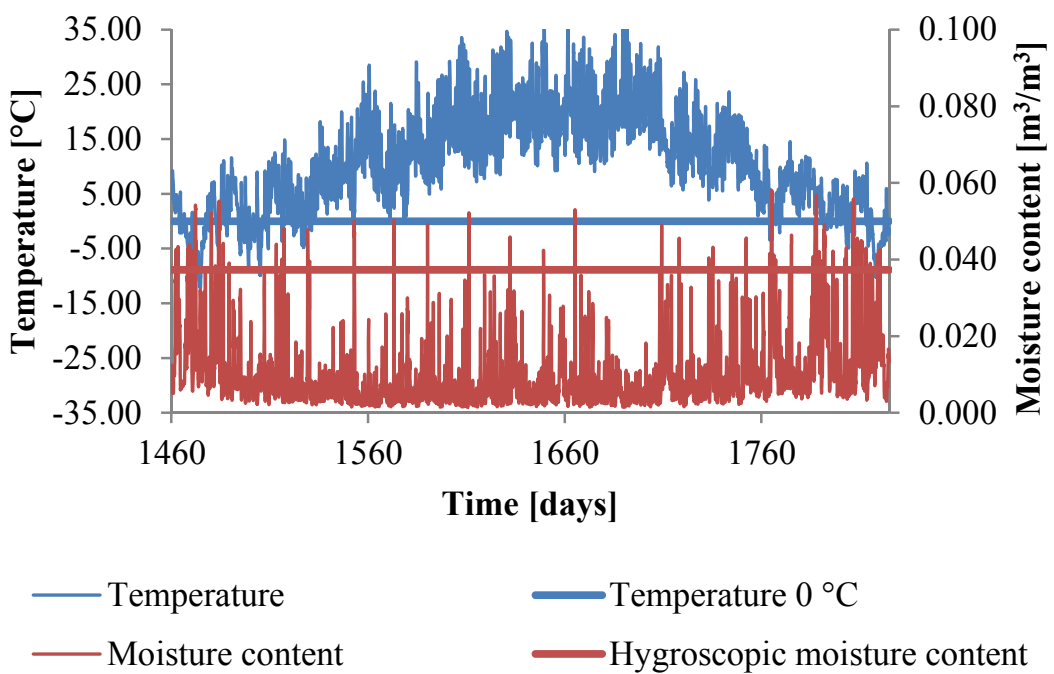

Figure 2: Hygrothermal performance of LCP applied on solid brick masonry.

such as ceramic powder or metakaolin as was done in this paper. Even if both admixtures led to a decrease of freeze/thaw resistance (see Table 3), hygrothermal performance of plasters were improved to such an extent that appearance of freeze/thaw cycles during reference year were eliminated in several cases.

Lime plaster with metakaolin admixture applied on sandstone masonry did not evince any signs of presence of freeze/thaw cycles during reference year which means, durability of LPMA will not be limited by its freeze/thaw resistance. The main reason of such behavior is obvious in Figure 3, as the moisture content reached overhygroscopic range only during summer period. Therefore, in winter there was not any liquid water which could get frozen. One freeze/thaw cycle was counted in LPMA applied on brick masonry. Based on that, the first signs of damage can be expected after 40 years.

In the case of lime plaster with addition of ceramic powder, the results are not optimal in all cases. While LPC applied on sandstone did not evince any freeze/thaw cycle, after application on solid brick masonry there were four cycles counted (see Figure 4). Together with very poor freeze/thaw resistance, it makes LPC inapplicable on solid bricks. However, properties of LPCs are very different based on amount of ceramic powder addition as was proved by Maděra et al. [5]. Moreover, this research is in early stage, therefore improvement of properties of plasters with powder ceramics can be expected in the nearest future. These expectations can be furthermore intensified by the fact, that ceramic powder with pozzolanic properties is ready-to-use waste product from brick industry and its application has also an environmental effect. 

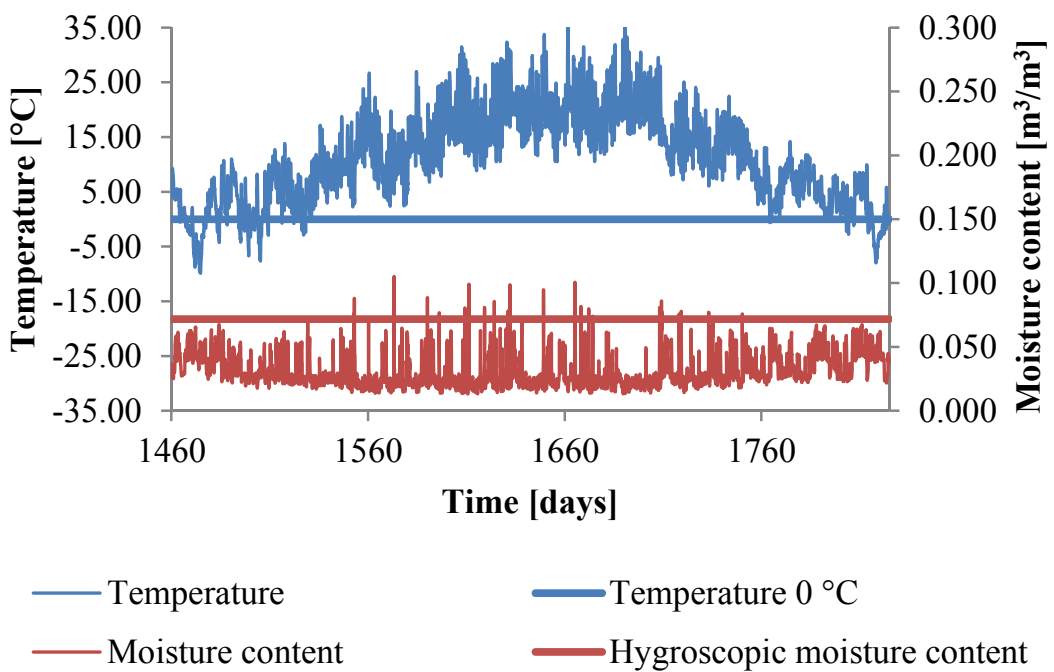

Figure 3: Hygrothermal performance of LPMA applied on sandstone masonry.
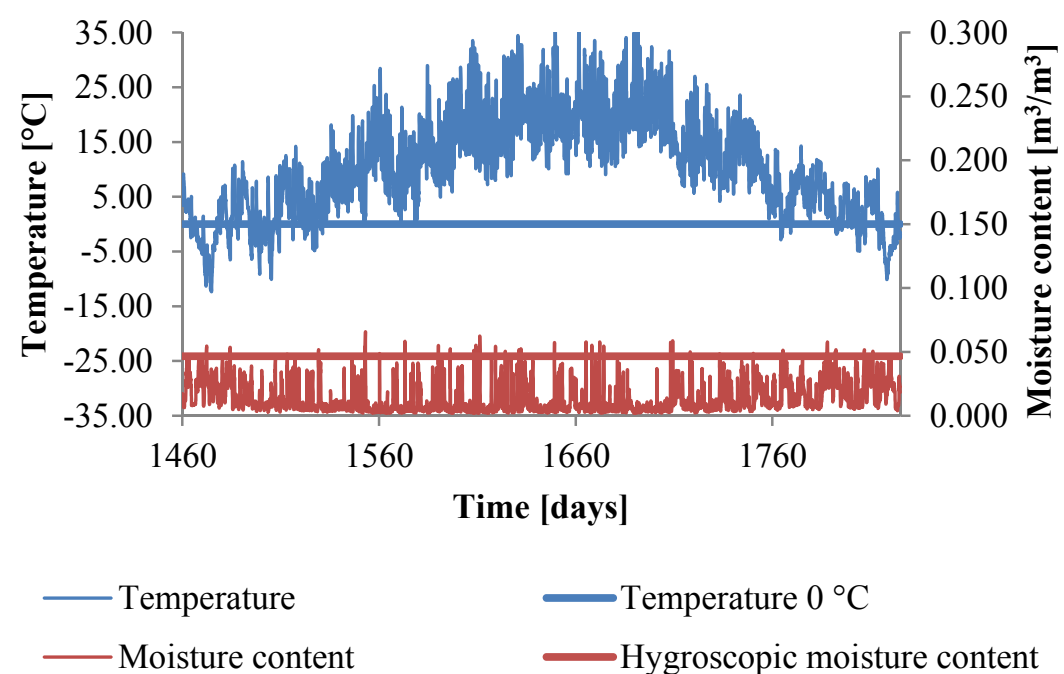

Temperature $0{ }^{\circ} \mathrm{C}$
Hygroscopic moisture content

Figure 4: Hygrothermal performance of LPC applied on solid brick masonry.

The service life of analyzed building envelopes is summarized in Table 4 together with duration of moisture in liquid phase.

Apparently, based on material characteristics of plasters presented in Table 2, the differences in hygrothermal performance of particular plasters are primarily 
Table 4: Summary of service life, freeze/thaw cycles and liquid moisture appearance.

\begin{tabular}{|l|c|c|c|c|c|c|}
\hline \multirow{2}{*}{} & \multicolumn{3}{|c|}{ Solid brick } & \multicolumn{3}{c|}{ Sandstone } \\
\cline { 2 - 7 } & LCP & LPC & LPMA & LCP & LPC & LPMA \\
\hline $\begin{array}{l}\text { Appearance of liquid water } \\
\text { [h] }\end{array}$ & 154 & 74 & 63 & 192 & 39 & 48 \\
\hline Freeze/thaw cycles & 8 & 4 & 1 & 6 & 0 & 0 \\
\hline Service life estimation [years] & 13 & 1.25 & 40 & 17 & - & - \\
\hline
\end{tabular}

determined by their hygric properties. While thermal conductivities are very similar, apparent moisture diffusivities differ up to one order of magnitude. It has significant influence on hygric performance of plasters and thus on their durability. The differences of moisture and temperature profiles are captured in Figures 5 and 6 . In these figures, position $0 \mathrm{~mm}$ denotes the interior side of the building envelope and the vertical dot lines denote the material interfaces.

While the differences in temperature profiles are marginal (no more than $1.19^{\circ} \mathrm{C}$ ), the relative humidity profiles differ up to $11.25 \%$ due to different hygric properties of plasters. Such a difference in relative humidity profiles ensures variability of appearance of freeze/thaw cycles case by case.

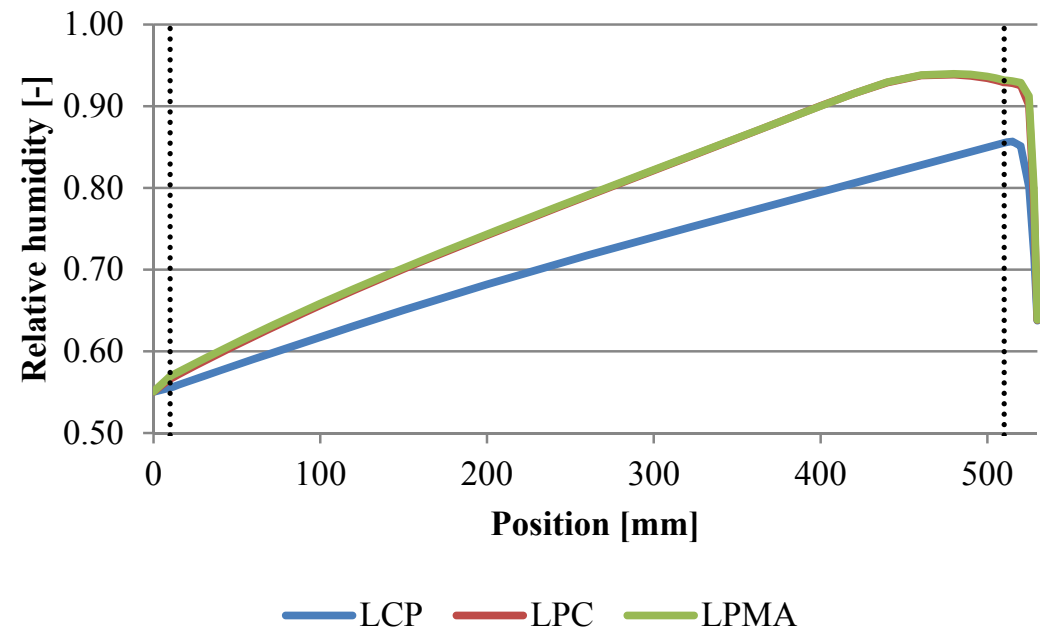

Figure 5: Relative humidity profiles; solid brick; 31 st of January. 


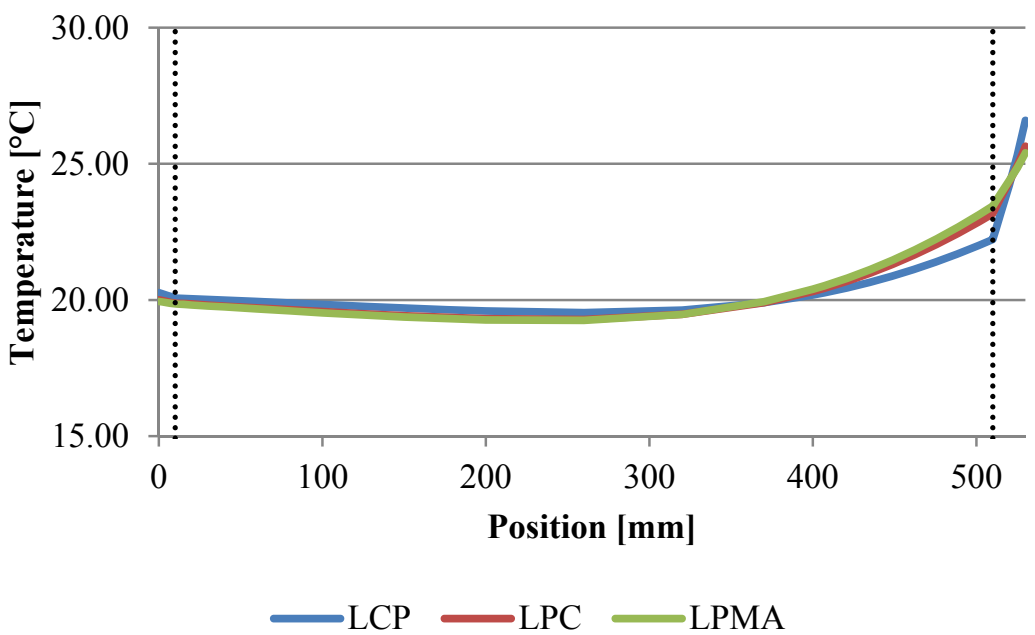

Figure 6: Temperature profiles; sandstone; 31st of July.

\section{Conclusions}

A combined experimental-computational approach for the estimation of service life of historical building envelopes provided with renovation plasters was presented in this paper. As the load bearing material, solid brick and sandstone were assumed. These walls were then provided with lime-cement plaster (LCP), lime plaster with metakaolin addition (LPMA) and lime plaster with addition of ceramic powder (LPC). All the material parameters of involved materials were measured in laboratories of transport processes at the Department of Materials Engineering and Chemistry, Faculty of Civil Engineering, Czech Technical University in Prague. The calculations were performed using the mathematical modelling of coupled heat and moisture transport with dynamic climatic data of Prague by finite element method.

The results indicated that it is not necessary to insist on materials commonly available on the market. It is more appropriate to focus on hygrothermal properties of plaster instead of mechanical. For instance, even if lime-cement plaster, representing the traditional finishing material, has the best mechanical properties from all the investigated plasters and is capable to resist the effect of more than 100 freeze/thaw cycles, its service life from point of view of freeze/thaw resistance will still be shorter than service life of lime plaster with metakaolin. This is caused by fact that LPMA allowed presence of only one freeze/thaw cycle per reference year at most, while in the case of LCP there were up to eight cycles. Summarizing the hygrothermal performance of analyzed plasters together with their freeze/thaw resistances, the best service life was achieved when LPMA was assumed. In this case, the first signs of damage may occur after 40 years, depending on the type of load bearing material. 


\section{Acknowledgement}

This research has been supported by the Ministry of Culture of the Czech Republic, under project No DF12P01OVV030.

\section{References}

[1] Černý, R., (ed). Complex System of Methods for Directed Design and Assessment of Functional Properties of Building Materials: Assessment and Synthesis of Analytical Data and Construction of the System, CTU Prague: Prague, 2010.

[2] Kruis, J., Koudelka, T. \& Krejčí, T., Efficient computer implementation of coupled hydro-thermo-mechanical analysis. Mathematics and Computers in Simulation, 80, pp. 1578-1588, 2010.

[3] Kočí, J., Kočí, V., Maděra, J., Rovnaníková, P. \& Černý, R., Computational analysis of hygrothermal performance of renovation renders. Proc. of the $11^{\text {th }}$ Int. Conf. on Advanced Computational Methods and Experiments in Heat Transfer 2010, ed. C.A. Brebbia, Southampton: WIT Press, pp. 267-277, 2010.

[4] Maděra, J., Kočí, V., Vejmelková, E., Černý, R., Rovnaníková, P., Ondráček, M. \& Sedlmajer, M., Influence of material characteristics of concrete and thermal insulation on the service life of exterior renders. Proc. of the $14^{\text {th }}$ Int. Conf. on Computational Methods and Experimental Measurements 2009, ed. C.A. Brebbia, Southampton: WIT Press, pp. 1323, 2009.

[5] Maděra, J., Kočí, J., Vejmelková, E., Čáchová, M., Jerman, M. \& Černý, R., Service life assessment of exterior lime-pozzolan renders containing ceramic powder. Proc. of the $17^{\text {th }}$ Int. Conf. on Computational Methods and Experimental Measurements, ed. C.A. Brebbia, Southampton: WIT Press, in press, 2015.

[6] Kočí, V., Maděra, J., Fořt, J., Žumár, J., Pavlíková, M., Pavlík, Z. \& Černý, R., Service life assessment of historical building envelopes constructed using different type of sandstones: A computational analysis based on experimental input data. The Scientific World Journal, 2014 (1), pp. 1-12, 2014.

[7] Pavlík, Z., Kulovaná, T., Žumár, J., Pavlíková, M. \& Černý, R., Experimental analysis of material properties of historical ceramic bricks and their potential current replacement. Proc. of the $14^{\text {th }}$ Int. Conf. on Studies, Repairs and Maintenance of Heritage Architecture, ed. C.A. Brebbia, Southampton: WIT Press, in press, 2015.

[8] Černý, R., (ed). Complex System of Methods for Directed Design and Assessment of Functional Properties of Building Materials and Its Application, CTU Prague: Prague, 2013.

[9] Künzel, H.M. Simultaneous Heat and Moisture Transport in Building Components, Ph. D. Thesis, IRB Verlag: Stuttgart, 1995. 
[10] Kočí, V., Maděra, J. \& Černý, R., Computer aided design of interior thermal insulation system suitable for autoclaved aerated concrete structures. Applied Thermal Engineering, 58 (1-2), pp. 165-172, 2013.

[11] Meteonorm, Version 6.0, software version 6.1.0.20 from April 2010. Meteotest, Switzerland.

[12] ČSN 73 0540-2 Thermal Protection of Buildings - Part 2: Requirements, Czech Office for Standards, Metrology and Testing, Prague, 2011. 